\title{
Prevalencia de Neospora caninum y DVB en una finca con problemas reproductivos en Sopó (Cundinamarca)
}

\author{
Neospora caninum and BDV prevalence in a farm \\ with reproductive problems in Sopó (Cundinamarca)
}

Fecha recepción: 13 de noviembre de 2013 Fecha Aprobación: 15 de enero de 2014
John Fredy García-Chaparro', Giovanni Moreno-Figueredo², Anastasia Catalina Cruz-Carrillo ${ }^{3}$

\begin{abstract}
RESUMEN
La investigación tuvo como objetivo determinar la prevalencia de Neospora caninum y del virus de la diarreaviral bovina(DVB) en bovinosdeunafincacon problemas reproductivos, en el municipio de Sopó (Cundinamarca), y su relación con la presentación de abortos. Se tomaron muestras de suero sanguíneo de 397 animales de alta producción lechera y con antecedentes reproductivos, seleccionados al azar. Se utilizó la inmunofluoresencia indirecta para la N. caninum, y seroneutralización para DVB, y los procedimientos se realizaron en el Laboratorio de Enfermedades Infecciosas de la Universidad de Parma (Italia). Se encontró una prevalencia de $10.37 \%$ para DVB con respecto a $21.26 \%$ para $N$. caninum, y estadísticamente no hubo relación directa con respecto a los problemas reproductivos. De acuerdo con los resultados obtenidos, se reportó mayor presencia significativa de $N$. caninum con relación a la de DVB en el hato lechero objeto de estudio.
\end{abstract}

Palabras clave: Neóspora, Diarrea Viral Bovina, enfermedades infecciosas.

\begin{abstract}
The research objective was to determine the Neospora caninum and the bovine viral diarrhea virus prevalence in a cattle farm, with reproductive problems in the Bogotá Sabana region, and their relation to the abortions incidence. Blood serum samples were taken from 397 high milk production animals, with randomly selected reproductive history. These animals were located in the Sopó muncipality (Cundinamarca Departament). The indirect immunofluorescence was used for $\mathrm{N}$. caninum and the serum neutralization for BVD. The procedures were performed in the Infectious Diseases Laboratory at the Parma University (Italy). The study showed a $10.37 \%$ prevalence for BVD and $21.26 \%$ for N. caninum. Statistically there was no relationship with respect to reproductive problems. According to the results obtained, there was a more significant presence of $N$. caninum in relation to BVD, in the dairy herd under study.
\end{abstract}

Key Words: Neospora, BVD, Infection Diseases.

\footnotetext{
Universidad Juan de Castellanos (Tunja-Boyacá, Colombia). Ph.D. Universidad Juan de Castellanos (Tunja-Boyacá, Colombia).

M.Sc. Universidad Pedagógica y Tecnológica de Colombia (Tunja-Boyacá, Colombia). Correo electrónico: anastasia. cruz@uptc.edu.co
} 


\section{INTRODUCCIÓN}

Neospora caninum es un protozoario causante de fallas reproductivas (abortos, mortalidad neonatal y mayor número de días abiertos y de inseminaciones) en hembras bovinas; los caninos son sus hospedadores definitivos, y eliminan el parásito por materia fecal, contaminando las pasturas; igualmente, se cree que hay transmisión vertical $(1,2,3)$. El virus de la diarrea viral bovina (DVB) es otro de los agentes etiológicos de las enfermedades reproductivas que afectan a los bovinos $(4,5,6)$; se trata de un pestivirus que ingresa por las mucosas y se replica a nivel epitelial, afectando el sistema respiratorio, digestivo y reproductivo. Según estudios realizados a nivel mundial con hembras bovinas, en unos casos se encuentran bajas prevalencias de DVB, aproximadamente del $5 \%$ (7), en otros se reportan cercanas al $50 \%$ (8) y en algunos más superan el $90 \%$ (9). N. caninum se ha reportado con prevalencias entre $2 \%$ y $40 \%(10,11,12)$. Las dos enfermedades están diagnosticadas en Colombia, y aunque existen variaciones en las diferentes regiones del país, se reconocen como causas de abortos en diferentes explotaciones ganaderas (5).

En busca de diseñar los planes de control de estas y otras enfermedades presentes en los hatos lecheros, es necesario hacer un diagnóstico sanitario de cada predio, estudios que en algunas partes del país se han realizado. En el municipio de Sopo no se han realizado trabajos para diagnosticar la presencia de DVB y de $N$. caninum, a pesar de reportarse alta incidencia de problemas reproductivos. Por lo anterior, con este trabajo se busca determinar si la alta incidencia de problemas reproductivos en una finca lechera representativa de la región se debe a la prevalencia de N. caninum y DVB.

\section{MATERIALES Y MÉTODOS}

Lugar de estudio. El proyecto se realizó en una finca de alta producción lechera ubicada en el municipio de Sopó (Cundinamarca), a 2.650 msnm y con una temperatura promedio de $14{ }^{\circ} \mathrm{C}$; cuenta con una extensión de 150 hectáreas, con una topografía plana; maneja un sistema intensivo de producción de leche, y tiene sembrado pasto kikuyo y raygrass, trigo y cebada.
Animales. La finca cuenta con un promedio de 900 hembras bovinas, entre terneras, novillas y vacas adultas, de las razas Holstein negro y rojo, algunas de las cuales con antecedentes de aborto y problemas reproductivos. Se maneja un sistema de producción mixto, ya que se encuentran animales semiestabulados, estabulados y en pastoreo, según el grupo etáreo y las consideraciones particulares de producción. Para la alimentación de los animales se manejan gramíneas, como el kikuyo en pastoreo y el raygrass para corte. Para el estudio se seleccionaron al azar 397 animales: terneras $(N=43)$, novillas $(N=83)$ y vacas adultas en producción y en período seco (269). Se incluyeron dos toros en el muestreo.

Toma y manejo de muestras. Previa desinfección, se tomaron de la vena coccígea $8-10 \mathrm{ml}$ de sangre, que posteriormente fueron pasados a tubos tapa roja (sin anticoagulante), etiquetados y almacenados en una cava con hielo en gel. La información reproductiva de cada animal muestreado fue registrada para el posterior análisis. Las muestras fueron centrifugadas a $2500 \mathrm{rpm}$ para la obtención del suero, que se almacenó a $-20{ }^{\circ} \mathrm{C}$ hasta su envío por correo certificado, con todos los permisos exigidos por el ICA y por el país receptor. Las muestras fueron recibidas en el Laboratorio de Microbiología de la Universidad de Parma (Italia), donde fueron procesadas mediante las técnicas indicadas para cada uno de los agentes, previa verificación de que los tubos llegaron en buenas condiciones y de que la temperatura se mantuvo en lo indicado $\left(-20^{\circ} \mathrm{C}\right)$.

Pruebas de laboratorio. El diagnóstico de $N$. caninum se hizo por la técnica de inmunofluoresencia indirecta (IFI), para lo cual una muestra de $10 \mathrm{mcl}$ de suero se colocó en cada uno de los pozos de una lámina específica que contiene el antígeno. Después de haber distribuido la muestra se puso la lámina en la cámara húmeda, que se incubó a $37{ }^{\circ} \mathrm{C}$ durante una hora, para luego lavar la lámina sumergiéndola 30 veces en PBS (solución isotónica, que ayuda a mantener la integridad de la célula), y otras 30 veces en agua destilada. Después del lavado, se agregó a cada pozo el anticuerpo secundario (antiglobulina 100 mcl) y se adicionó azul de Evans, el cual sirve para mejorar la lectura. Posteriormente se incubó durante una hora a $37{ }^{\circ} \mathrm{C}$ en cámara húmeda; al 
cabo del tiempo se lavó nuevamente la lámina con PBS (30 veces) y agua destilada (30 veces). Se dejó secar a medioambiente y se llevó la lámina a lectura con microscopio fluorescente (13).

El diagnóstico de DVB se hizo por medio de la prueba de seroneutralización (SN), que consiste en identificar y valorar la capacidad de los anticuerpos séricos para neutralizar el efecto citopático de una cepa. Dicha prueba se realizó diluyendo los sueros problema, el suero control positivo y control negativo en base 2, en volúmenes de $50 \mathrm{mcl}$, y se enfrentaron a 100 dosis infectantes en cultivo de tejido $50 \%\left(\mathrm{DICT}_{50}\right.$ ) de la cepa viral NADL del VDVB, también en volúmenes de $50 \mathrm{mcl}$. Luego se incubó durante 60 minutos a temperatura ambiente, se adicionaron $100 \mathrm{mcl}$ de células embrionarias de pulmón bovino de segundo pasaje ( $\left.1 \times 10^{6} \mathrm{cél} / \mathrm{ml}\right)$, en MBDK, más $10 \%$ de suero fetal bovino irradiado (SFB). Finalmente, las microplacas se llevaron a incubación en estufa de cultivo con cámara húmeda a $37{ }^{\circ} \mathrm{C}$ y adicionada de un $5 \%$ de $\mathrm{CO}_{2}$, durante 5 días, para luego proceder a su lectura mediante observación microscópica.
Para la interpretación de la prueba de SN se observó la presencia de CP en los diferentes pocillos de cada microplaca. Se revisaron todos los sueros y se hizo la lectura de los pocillos correspondientes a cada dilución sérica (13).

Los resultados se expresaron en términos de muestras positivas y negativas. En el caso de la DVB se interpretó positivo cuando se obtuvieron títulos en diluciones iguales o superiores a 126, y negativo cuando fueron inferiores a 126 . Con la $N$. caninum se interpretó como positivo con títulos iguales o mayores a 400, y como negativo cuando estos estuvieron por debajo de dicho valor (13).

\section{RESULTADOS Y DISCUSIÓN}

Prevalencia de $\boldsymbol{D} \boldsymbol{V} \boldsymbol{B}$. Del total de animales muestreados (397), el $10,37 \%$ (41) resultaron positivos a DVB, siendo mayor en terneras (6/43), seguidas por vacas $(29 / 269)$ y por novillas $(6 / 83)$. Los toros resultaron negativos (Figura 1).

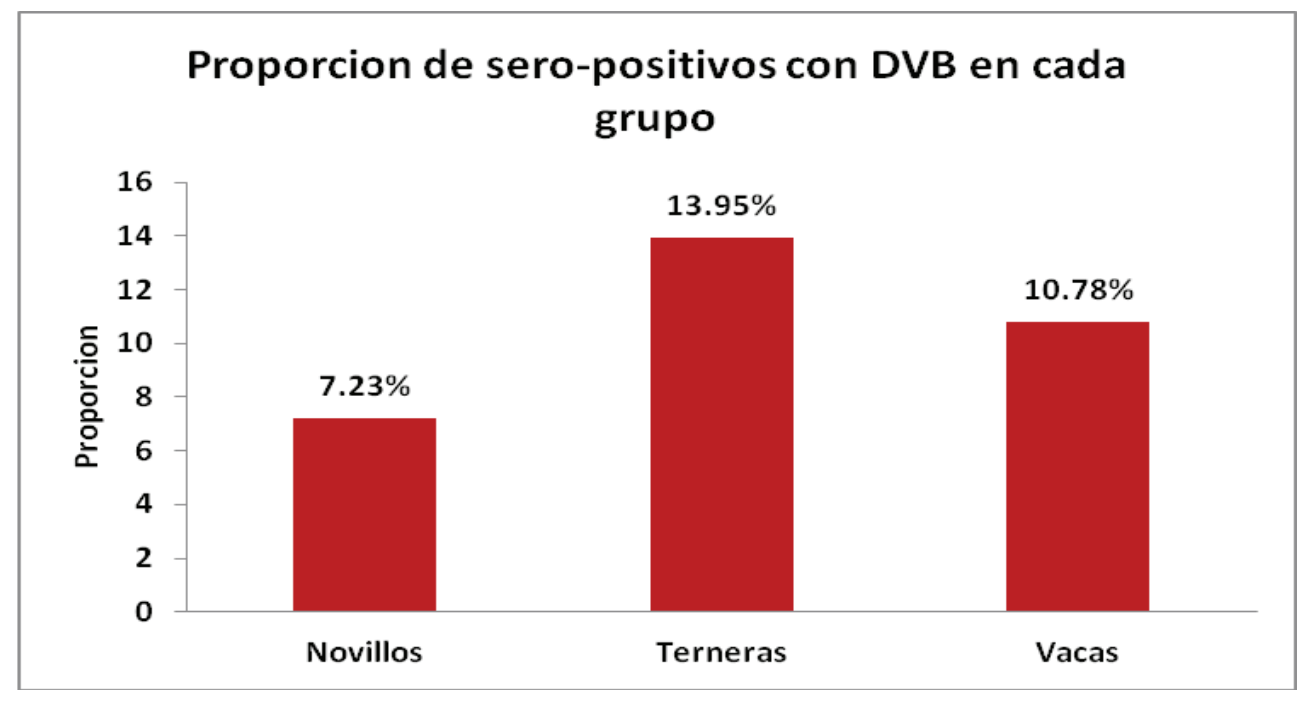

Figura 1. Prevalencia de DVB según grupo etáreo

Relación DVB con problemas reproductivos. Mediante una tabla de $2 \times 2$ se determinó la relación entre la positividad a DVB y la repetición de celos, encontrando que de 10 hembras positivas estudiadas, una presentaba repetición de celo, y el resto no, y de 90 hembras negativas a la enfermedad, 10 mostraban repetición de celo, y el resto no. De la misma manera, se estudió la relación de la presencia de la enfermedad con el reporte de abortos, encontrando que de las 10 hembras positivas a DVB ninguna tuvo aborto, $y$ de las 90 negativas, 88 no mostraron dicha alteración. 
Buscando determinar si hubo diferencia entre las prevalencias entre animales seropositivos $y$ seronegativos, se encontró que existe diferencia significativa $\left(p=2.6802 \mathrm{E}-56 ; p<0.05 ; \mathrm{chi}^{2}=249.94\right)$ entre los individuos seronegativos $(89.7 \%)$, que son la mayoría, y los seropositivos (10.3\%). Estos resultados difieren de los encontrados por Parra, citado por (4), donde se indica una seroprevalencia de $89 \%$ en la Sabana de Bogotá. Igualmente, se encontró menor prevalencia en esta finca que lo encontrado en Montería (Colombia), donde fue de $29.4 \%$ (14). En otros países se encuentran prevalencias de hasta $96 \%$, en la IX región de Chile, zona eminentemente lechera (15).

El análisis de los datos indicó que dentro de la población de animales positivos a DVB $(\mathrm{N}=41)$, el $70,73 \%$ fueron vacas; el $14,63 \%$, novillas, e igual proporción, terneras; lo anterior determina que, según la prueba $(p=2.4920 E-06 ; p<0.05$; chi $^{2}=25.80$ ), hubo diferencia significativa entre unas y otras; sin embargo, este mayor porcentaje encontrado en adultas se explica porque hay más individuos dentro del grupo etáreo vacas que en el de novillas o terneras. Por lo anterior, para determinar si hay más seropositivos en algún grupo se realizó otra prueba $\mathrm{Chi}^{2}$, con la cual no se encontró diferencia estadísticamente significativa $\left(p=0.3457 ; p \geq 0.05 ; c h i^{2}=2.12\right)$ entre los tres grupos etáreos, pero la mayor proporción de seropositivas se encontró en el grupo de terneras, seguido por el de vacas, y la menor en novillas.

La positividad encontrada en las terneras puede tener varias explicaciones: son animales enfermos, y los anticuerpos son producto de la presencia del virus; son terneras normales con anticuerpos precalostrales; son terneras con anticuerpos vacunales, que pasan por el calostro y permanecen durante $60-80$ días, aproximadamente Por otra parte, se puede asegurar que ninguno de los seis animales positivos es persistentemente infectado, debido a que este tipo de animales no tiene anticuerpos, por lo cual son seronegativos, y si se quisiera investigar en la explotación cuáles son estos, tendría que hacerse una prueba de Elisa indirecta o por PCR $(6,16,17)$.

Por otra parte, los resultados aquí encontrados coinciden con otro trabajo cuyos autores encontraron diferencias claramente significativas entre la prevalencia de la DVB, la raza, la edad, la época del año y el tipo de producción (18). Contrario a esto, en un trabajo realizado en Loja (Ecuador) encontraron que la edad de mayor presentación era de 1 a 4 años, y que hasta los 6 meses podían ser positivos por anticuerpos maternos, con similares resultados (19). Así mismo, otros reportan que la seropositividad de DVB aumenta con la edad; sin embargo, en neonatos se encuentra alta prevalencia, posiblemente por la presencia de anticuerpos calostrales, y la mayor prevalencia es encontrada en animales de tres y cuatro partos $(20,21)$.

Respecto a la influencia del VDVB sobre el desempeño reproductivo y la repetición de celo, la prueba estadística $(p=0.6785 ; p \geq 0.05)$, mediante la prueba de Fisher, indicó que la presencia del virus no influyó sobre la repetición de calores en los animales de este estudio. Contrario a los resultados encontrados en esta investigación, en 2009 encontraron que el $31.3 \%$ de los animales muestreados fueron vacas repetidoras (21). El virus de la diarrea viral bovina es uno de los agentes infecciosos incluidos dentro de aquellos que producen infertilidad, debido a que se reporta muerte embrionaria, manifestada por repetición de celo (20); sin embargo, en este estudio dicho efecto no fue evidente en los animales positivos.

Analizando los resultados de la influencia de la DVB sobre la presentación de abortos $(p=0.4772$; $p \geq 0.05$ ), se encontró que bajo las condiciones planteadas en este estudio la presencia de abortos no parece estar relacionada con esta enfermedad. Como se dijo anteriormente, el virus de la diarrea viral bovina tiene efectos reproductivos caracterizados por aborto, momificación, malformaciones congénitas y muerte perinatal (18), sin embargo, en este estudio no se encontró relación directa entre la presencia del virus y dichos efectos. Estos resultados tampoco coincidieron con otros trabajos, como uno en el que encontraron que el $11.3 \%$ de los fetos abortados eran positivos a la enfermedad, y otro en el que el $14.5 \%$ de los animales positivos tuvieron aborto $(14,22)$.

Prevalencia de Neospora caninum. La prevalencia encontrada en la finca fue de $21,26 \%$, que corresponde a 84 animales positivos de los 397 muestreados, siendo mayor en novillas (27/83), seguidas por las vacas $(51 / 269)$ y luego las terneras (6/43). Los toros también resultaron negativos (Figura 2). 


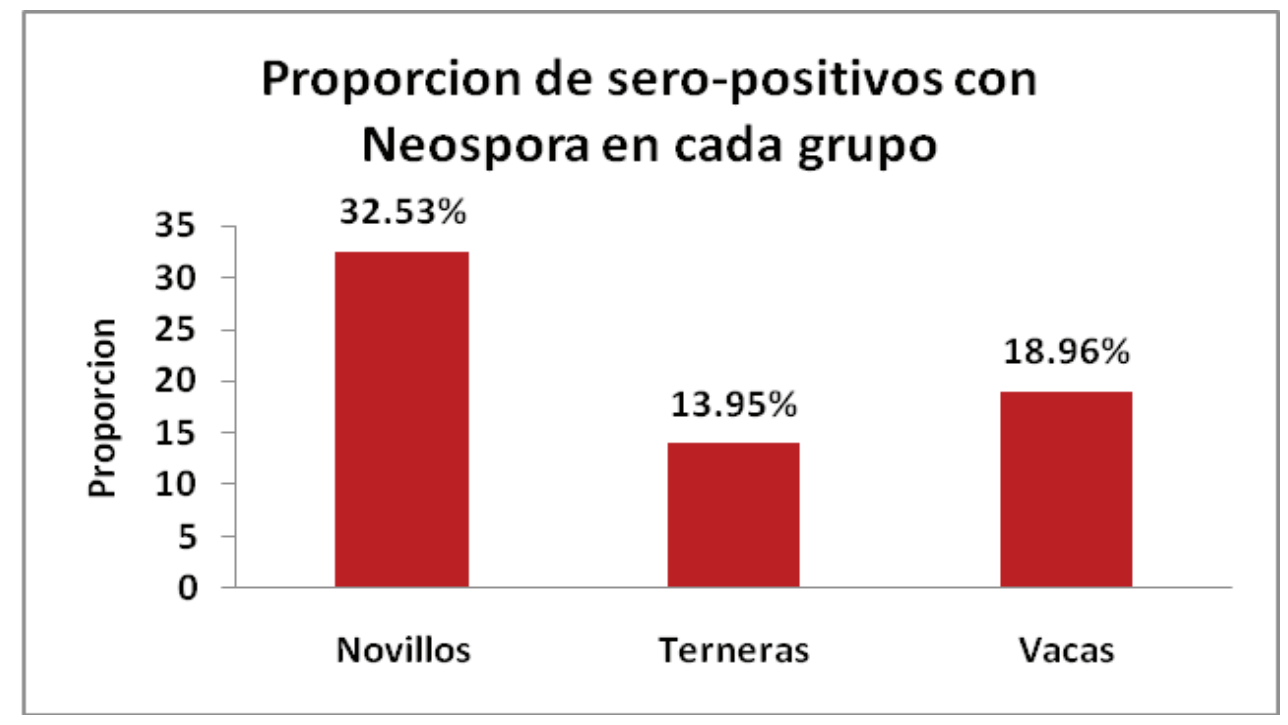

Figura 2. Prevalencia de N. caninum según grupo etáreo

\begin{abstract}
Relación de Neospora caninum con problemas reproductivos. De los 21 animales estudiados para determinar efectos reproductivos, solo uno ha presentado aumento de los días abiertos, y de las 79 negativas, 68 no mostraron aumento de este parámetro reproductivo. Por otra parte, solo una de las hembras positivas tuvo reporte de aborto, y de las 79 negativas, 68 no tuvieron reporte de esa alteración.
\end{abstract}

Con relación a la seroprevalencia, la prueba indica $\left(p=1.4275 \mathrm{E}-30 ; \quad p<0.05 ; \quad \mathrm{chi}^{2}=132.09\right)$ que existe diferencia significativa entre el número de individuos seronegativos (78.84\%), que fueron la mayoría, y los seropositivos (21.16\%). La prevalencia aquí encontrada, aunque similar, fue superior a la de otros trabajos, en los que fue 3.5\% y $18.1 \%(23,24)$, pero inferior a otros, en los que fue $28.5 \%$ (25). La presencia de este parásito se relaciona con errores de manejo en comederos y bebederos, así como la introducción de animales infectados y la presencia de perros, ya que finalmente son la principal fuente de transmisión y donde el parásito realiza su fase sexual y posterior replicación (10).

En este estudio, la mayoría de individuos seropositivos a Neóspora fueron vacas $(60.71 \%)$, seguidas de las novillas $(32.14 \%$ ) y las terneras (7.14\%). Según el análisis estadístico $(p=1.37 \mathrm{E}-08$; $\left.\mathrm{p}<0.05 ; \mathrm{chi}^{2}=36.21\right)$, se encuentra que hay diferencia significativa entre la positividad en los grupos etáreos, sin embargo, esta parece deberse a que en el muestreo hubo mayor número de vacas que en los otros dos grupos. Por lo anterior, se hizo necesario realizar otra prueba de chi cuadrado, que indicó que de la población total de animales positivos al parásito $(\mathrm{N}=84)$, hay diferencia estadística $\left(p=0.0144 ; p<0.05 ;\right.$ chi $\left.^{2}=8.47\right)$ en los tres grupos etáreos, siendo las novillas las de mayor proporción de seropositivas, seguidas por el grupo de vacas y, en tercer lugar, por el de las terneras.

Los resultados del presente estudio fueron similares a los de un trabajo realizado en Chile, en donde se encontró que la mayor proporción de animales positivos a Neospora eran novillas, seguidas por vacas y terneras (26).

Por otra parte, el análisis de la relación entre la presencia del parásito y la repetición de calores, de acuerdo con la prueba de Fisher $(p=0.0148$; $\mathrm{p}<0.05)$, indicó que la presencia de $N$. caninum no está relacionada con dicha alteración. Sin embargo, lo reportado por la literatura es que este parásito induce muerte embrionaria que conduce a la repetición de celo (20), mientras que en otro estudio el $9.75 \%$ de los animales positivos al parásito fueron vacas repetidoras de celo (11). 
Con relación a los abortos, la prueba deFisher indicó que la presencia de Neóspora es independiente de la presencia de aborto $(p=0.9931)$. De manera similar a la repetición de estro, se reporta que el parásito produce aborto y momificación fetal $(2,27,28,29)$; sin embargo, en este trabajo no se encontró relación con significancia estadística entre la enfermedad y el problema reproductivo. Igualmente, este resultado no coincidió con Fernández et al. (14), en cuyo estudio de 115 fluidos de cavidades fetales, analizados mediante inmunofluoresencia indirecta, encontraron 15.6\% de positividad al N. caninum. En otro trabajo, con resultado similar, se encontró que de los animales muestreados y positivos al parásito, el $10.76 \%$ presentaron abortos (11).

Otro de los objetivos del presente trabajo fue determinar si la presencia de una enfermedad predispone a la presencia de la otra, por lo cual se comparó el número de individuos seronegativo para ambos (280 individuos), seropositivos para Neóspora (76 individuos), seropositivos para DVB (33 individuos) y seropositivos para ambos (8 individuos), y se encontró que la presencia del virus de la DVB no tiene relación directa con la presencia de N. Caninum, por lo que para este estudio no existe relación directa entre la presencia de las enfermedades. Este resultado coincide con un trabajo en el que evaluaron la prevalencia de varias enfermedades en un hato, y a pesar de no encontrar seropositividad a DVB, se encontró $N$. caninum (5).

\section{CONCLUSIONES}

Con los resultados obtenidos en el presente trabajo y bajo las condiciones planteadas, se puede afirmar que en el lugar de estudio hay mayor seropositividad a Neóspora que a DVB, y esta última se encontró en mayor proporción en el grupo de terneras, y en vacas adultas la mayor prevalencia fue de Neóspora. Otro hallazgo importante fue que no hubo relación entre la presentación de una y otra enfermedad y que ninguna de las dos influyó en el desempeño reproductivo de los animales del estudio. Buscando confirmar los resultados se puede sugerir un segundo muestreo en todos los animales utilizando como técnica una prueba de ELISA dirigida a la proteína P80 (Ns2-3). Igualmente, para el control futuro de la DVB se sugiere identificar los animales persistentemente infectados, a partir de lo cual se puede diseñar un protocolo de erradicación.

\section{AGRADECIMIENTOS}

Al Laboratorio de Enfermedades Infecciosas de la Universidad de Parma (Italia) y al Dr. Bernardo Guerrero.

\section{REFERENCIAS}

(1) Dubey J, Barr B, Barta J. Redescription of Neóspora caninum and its differentiation from related coccidia. International Journal of Parasitology 2002; 32: 929-946.

(2) Dubey J.P, Schares G, Ortega M. Epidemiology uncontrolled of neosporosis and Neóspora caninum. Clinica Microbiology Reviews 2007; 20(2): 323-367.

(3) Maley Sw, Buxton D, Rae Ag, Wright Se, Schock A, Bartley P.M. The pathogenesis of neosporosis in pregnant cattle: inoculation at mid-gestation. J. Comp. Path 2003; 129:186195.

(4) Gómez J. Seroprevalencia del virus de la diarrea vírica bovina en ganado bovino en Andalucía. Redvet, Revista Electrónica de Veterinaria 2009; 10(2):1695-7504.

(5) Rivera H. Evolution of the understanding of bovine viral diarrhea and its etiological agent. Rev. Investig. Vet. Perú 2008; 19 (2): 93-112.

(6) Vargas D, Jaime J, Vera V. Perspectivas para el control del virus de la diarrea viral bovina (DVB). Revista Ciencias Pecuarias 2009. 22:677-688.

(7) Aguilar R, Benito A, Rivera H. Seroprevalencia del virus de la diarrea viral bovina en ganado lechero de crianza intensiva del valle de lima. Rev InvVet Perú 2006; 17 (2):148-153.

(8) Huaman J.C, Rivera H, Arainga M, Gavidia C, Manchego A. Diarrea viral bovina y animales portadores del virus en hatos productores de leche de la irrigación de Majes, Arequipa. Rev. Inv. Vet. Peru 2007; 18(2) 141-149. 
(9) Machado A, García M, Silveira E. Determinación de los factores de riesgo y adecuación de medidas de recuperación en un foco de diarrea viral bovina. Redvet Rev. electrón. Vet. Cuba 2010; 11 (03B) 1700-1711.

(10) Quevedo J.V, Chávez A, Rivera H, Casas E, Serrano E. Neosporosis en bovinos lecheros en dos distritos de la provincia de Chachapoyas. Rev. Inv. Vet. Perú 2003; 14 (1): 36-37.

(11) Oviedo T, Betancourt C, Alberto M, Marco G, Reza L, Calonge K. Estudio serológico sobre la neosporosis en bovinos con problemas reproductivos en Montería (Córdoba, Colombia). Revista MVZ Córdoba 2007; 12 (1): 929-933.

(12) Obando C, Bracamonte M, Montoya A, Cárdenas V. Neospora caninum en un rebaño lechero y su asociación con el aborto. Rev. Científica Venezuela FCV-LUZ 2010; 20 (3) 235-239.

(13) Moreno G. Serological survey of bovine infectious causes of reproductive disorders in Colombia. Tesis de Doctorado en Salud Animal, Universita Degli Studi Di Parma, 2012.

(14) Fernández $M$, Campero C, Morrell E, Cantón G, Moore D, Cano A, Malena R, Odeón A, Paolicchi F, Odriozola E. Pérdidas reproductivas en bovinos causadas por abortos, muertes prematuras, natimortos y neonatos: casuística del período 2006-2007. (Buenos Aires) Rev. Med. Vet 2009; 88 (6): 246-254.

(15) Felmer R, Zuniga J, López A, Miranda $\mathrm{H}$. Prevalencia y distribución espacial de brucelosis, leucosis bovina, diarrea viral bovina y rinotraqueítis infecciosa bovina a partir del análisis ELISA de estanques prediales en lecherías de la IX Región, Chile. Arch. Med. Vet 2009; 41 (1): 17-26.

(16) Singh K, Miller M.M; Kohtr L.J, Scherba G, Garret E.F, Fredrickson R.L. Development of a novel diagnostic test for detection of bovine viral diarrhea persistently infected animals using hair. J. Vet Sci 2011; 12(3): 295-297.
(17) Logue D. Strategy for eradicating BVD from Scotland. Vet Rec 2011; 167 (21): 83-89.

(18) Jara C. Estudio de seroprevalencia de diarrea viral bovina (VDB) y rinotraqueítis infecciosa bovina (IBR) en la provincia de loja (ecuador) por medio de enzyme linked immunosorbent assay (Elisa) y su distribución epidemiológica geoespacial. Trabajo de grado; Escuela de ingeniería Agropecuaria, Universidad Católica de Loja, 2005.

(19) Betancur H, Gorgoza L, Martínez F. Seroepidemiología de la diarrea viral bovina en Montería (Córdoba, Colombia). Analecta Veterinaria 2007; 27 (2): 11-16.

(20) Mockeliuniene V, Salomskas A, Mockeliunas R, Petkevicius S. Prevalence and epidemiological features of bovine viral diarrhoea virus infection in Lituania. Veterinary Microbiological 2004; 13(2): 99-107.

(21) Pulido M, Andrade RJ, Arias S, Salamanca C, Agredo R. Dinámica poblacional de diarrea viral bovina en fincas lecheras del municipio de Sotaquirá Boyacá. Rev Colomb Cienc Pecuarias 2009; 22: 3.

(22) Celedon M, Palacios del V.L, Pizarro LJ, Ibarra LM. Prevalencia de anticuerpos seroneutralizantes para el virus de la diarrea viral bovina, en ganado de carne de la región metropolitana de Chile. Avances en Ciencias Veterinarias 1997; 12(2): 98-100.

(23) Puray N, Chaves A, Casas E, Falcon N, Casas G. Prevalencia de Neospora caninum en bovinos de una empresa ganadera de la sierra central del perú. Rev Inv Vet Perú 2006; 17(2): 189-194.

(24) Atocsa J, Chávez A, Casas E, Falcón N. Seroprevalencia de Neospora caninum en vacunos lecheros criados al pastoreo en la provincia de Melgar, departamento de Puno. Rev. Inv.Vet. Perú 2005; 15: 71-75.

(25) Gamón A, Villegas F, Quiroga C. Detección de anticuerpos de Neospora caninum en la zona norte de la cuenca lechera del departamento de Santa Cruz (Bolivia). Trabajo de grado, 
Facultad de Medicina Veterinaria y Zootecnia; UAGRM, 2003.

(26) Patitucci A, Pérez $M$, Israel $K$, Rozas $M$. Prevalencia de anticuerpos séricos contra Neospora caninum en dos rebaños lecheros de la IX Región de Chile. Arch Med Vet 2000; 32: 209-214.

(27) Björkman C, Mcallister MM, Frossling J, Naslund K, Leung F, Uggla A. Application of the Neospora caninum IgG avidity ELISA in assessment of chronic reproductive losses after an outbreak of neosporosis in a herd of beef cattle. J. Vet. Diagn. Invest 2003; 15: 3-7.
(28) Echaide IE. La neosporosis bovina. Jornada sobre enfermedades emergentes del Bovino. FAV UNRC, Río Cuarto (en línea), 2000. Disponible en http://www.produccionanimal.com.ar/sanidad_intoxicaciones metabolicos/enfermedades reproduccion/14la neosporosis_bovina.pdf

(29) Anderson M, Andrianarivo A, Conrad A. Neosporosis in cattle. An. Reprod. Sci 2000; 60 (61): 417-431. 